Eur J Clin Chem Clin Biochem

1995; 33:281-284

(ㄷ) 1995 Walter de Gruyter \& Co.

Berlin - New York

\title{
Determination of Alkaline Phosphatase Isozymes in Amniotic Fluid
}

\author{
By Adela Sembaj, Carlota Carriazo, Elizabeth Sanz and José Moreno Barral \\ Cátedra de Quimica Biológica, Facultad de Ciencias Médicas, Universidad Nacional de Córdoba, Córdoha, \\ Argentina
}

(Received July 28, 1994/February 7, 1995)

Summary: A simple method for the determination of the three isozymes of alkaline phosphatase (EC 3:1.3.1) contained in amniotic fluid (fetal intestinal, placental, and liver-bone-kidney) is presented. Total alkaline phosphatase activity was assayed in $10000 \mathrm{~g}$ supernatants of amniotic fluid from 30 normal women between the 16 th and 20 th week of pregnancy. Electrophoretic patterns and inhibition by $L$-phenylalanine and $L$-homoarginine studies showed that all the fetal intestinal isozyme was precipitated in the pellet after centrifugation at $100000 \mathrm{~g}$ for $90 \mathrm{~min}$. Thus, the difference between total alkaline phosphatase activity and activity in the $100000 \mathrm{~g}$ supernatant corresponds to fetal intestinal alkaline phosphatase. Placental isozyme can be determined by assaying alkaline phosphatase in the $100000 \mathrm{~g}$ supernatant after heating at $56^{\circ} \mathrm{C}$ for $90 \mathrm{~min}$. Liver-bone-kidney isozyme activity is obtained by subtracting placental alkaline phosphatase activity from that of the $100000 \mathrm{~g}$ supernatant. Mean percentages of the total alkaline phosphatase for each of the isozymes in amniotic fluid were $81 \%$ for fetal intestinal alkaline phosphatase, $7.5 \%$ for placental alkaline phosphatase and $12.0 \%$ for liver-bone-kidney alkaline phosphatase.

Determination of fetal intestinal alkaline phosphatase by this method could be applied to the diagnosis of cystic fibrosis in fetuses having a $1: 4$ risk of being affected.

\section{Introduction}

Human alkaline phosphatase (EC 3.1.3.1 $)^{1}$ ) exists as three isozymes with different tissue distribution: intestinal, placental and liver-bone-kidney. The three molecular forms can be identified on the basis of electrophoretic mobility, sensitivity to inhibitors, immunochemistry and heat stability (1). During the second trimester of pregnancy, amniotic fluid contains the three isozymes, although the intestinal form shows some differences to that found in adult intestinal microvilli. The fraction isolated from amniotic fluid is designated fetal intestinal alkaline phosphatase. The enzyme is located in the fetal small intestine mucosa. Since the microvilli are continuously desquamating into the lumen, their membranes and debris are incorporated into the meconium and normally pass to the amniotic fluid, especially during the

\footnotetext{
1) Enzyme

Alkaline phosphatase (EC 3.1.3.1)
}

second trimester of gestation (1). Fetuses affected by cystic fibrosis have a thickened meconium which slows down intestinal transit. Thus, less meconium is liberated to the amniotic fluid and the amount of fetal intestinal alkaline phosphatase in this fluid is substantially reduced $(2,3)$. Determination of activity in amniotic fluid between the 15th and 20th week of pregnancy has been proposed as a sensitive method for prenatal diagnosis of cystic fibrosis $(4,5)$. Thanks to the advances of molecular biology, other valuable diagnostic methods are available. Studies of restriction fragment length polymorphism of DNA segments of chromosome 7 indicated the existence of some "marker" restriction fragments linked to cystic fibrosis. Later isolation of the cystic fibrosis gene allowed a panel of probes to be obtained recognizing the most common mutations causing the disease. These techniques allow accurate diagnosis in a high percentage of cases $(6-8)$. However, even admitting the possibility of false positive and negative results (about $3 \%$ and $8 \%$, respectively) (4), enzyme determination in 
amniotic fluid is still a reliable method. It is approximately $90 \%$ accurate in cases of couples with cystic fibrosis and a $1: 4$ risk of having another cystic fibrosis baby (5). Presently available methods for fetal intestinal alkaline phosphatase determination involve use of monoclonal antibodies, availability of purified control isozymes or utilization of combined inhibitors, which complicate the procedure and are not simple enough for general use in the clinical laboratory $(9,10)$. We present here a method for the determination of isozymes of alkaline phosphatase in amniotic fluid and a simple technique for separation of fetal intestinal alkaline phosphatase.

\section{Materials and Methods}

\section{Amniotic fluid}

Thirty samples of amniotic fluid were obtained by amniocentesis of normal women being monitored for chromosomal abnormalities between the 16th and 20th week of pregnancy. The fluid was centrifuged at $1000 \mathrm{~g}$ for $10 \mathrm{~min}$ to separate suspended cells. The supernatant was centrifuged at $10000 \mathrm{~g}$ for $15 \mathrm{~min}$ to precipitate remaining debris. A $4 \mathrm{ml}$ aliquot of the supernatant was then centrifuged at $100000 \mathrm{~g}$ for $90 \mathrm{~min}$. The pellet was suspended in $0.2 \mathrm{ml}$ of $50 \mathrm{mmol} / \mathrm{l}$ Tris- $\mathrm{HCl}$ buffer, $\mathrm{pH} 7.0$ and used for enzyme assays and electrophoretic studies. A $2.0 \mathrm{ml}$ aliquot of the supernatant was incubated in a water-bath at $56^{\circ} \mathrm{C}$ for $90 \mathrm{~min}$ and then cooled on ice.

\section{Intestinal tissue}

Duodenum and jejunum were obtained within $24 \mathrm{~h}$ post-mortem at autopsy of adult human free of intestinal pathology. Mucosa was scrapped with a razor blade and stored at $-23^{\circ} \mathrm{C}$.

\section{Meconium}

It was obtained immediately after birth of normal babies and stored at $-23^{\circ} \mathrm{C}$ until used for enzyme extraction.

\section{Extraction of alkaline phosphatase}

Fetal and adult intestinal alkaline phosphatase were extracted from meconium and adult mucosa, respectively by butanolic treatment following the technique described by Morton (11).

\section{Enzyme assay}

Alkaline phosphatase (EC 3.1.3.1) assay was performed at $37^{\circ} \mathrm{C}$ in $2 \mathrm{ml}$ of a reagent mixture containing $3 \mathrm{mmol} / \mathrm{l} p$-nitrophenylphosphate, $0.5 \mathrm{mmol} / 1 \mathrm{MgCl}_{2}, 0.5 \mathrm{mmol} / \mathrm{l}$ diethanolamine $\mathrm{pH} 9.8$ and $0.3 \mathrm{ml}$ of the $10000 \mathrm{~g}$ supernatant of amniotic fluid. Reaction was stopped after $30 \mathrm{~min}$ by addition of 3 drops of $400 \mathrm{~g} / \mathrm{l} \mathrm{NaOH}$. Absorbance was read at $405 \mathrm{~nm}$. All determinations were carried out by duplicate and the activity expressed in Units per l of sample. One Unit is the amount of enzyme catalyzing the conversion of $1 \mu \mathrm{mol}$ of substrate per min in the assay conditions (12).

\section{Electrophoresis}

It was performed in $6.5 \%$ polyacrylamide gel with the micromethod described by Ogita \& Markert (13) after addition of $1 \mathrm{~g} / 1$ Triton X-100 to the preparation. The samples were run with 12.5 mmol/l Tris-glycine $\mathrm{pH} 8.3$ during $90 \mathrm{~min}$ at $200 \mathrm{~V}$ and $20 \mathrm{~mA}$ per gel. After electrophoresis was performed, alkaline phosphatase isozymes were revealed by staining with a mixture containing: $58 \mathrm{ml} 100 \mathrm{mmol} / \mathrm{l} \mathrm{Tris} / \mathrm{HCl} \mathrm{pH} 9.0,2 \mathrm{ml} \mathrm{MgCl} 250 \mathrm{mmol} / \mathrm{l}, 50 \mathrm{mg}$ $\alpha$-naphthyl acid phosphate monosodium salt and $25 \mathrm{mg}$ Fast Blue RR salt. The mixture was filtered and used immediately, staining was performed in the dark (14).

\section{Results}

Characterization of the alkaline phosphatase isozymes in amniotic fluid

The $100000 \mathrm{~g}$ pellet suspended in $50 \mathrm{mmol} / \mathrm{l}$ Tris- $\mathrm{HCl}$ buffer $\mathrm{pH} 7.0$ was submitted to electrophoresis after addition of Triton X-100. Specific staining for alkaline phosphatase revealed a zone of intense activity (fig. 1A). Without Triton X-100, all the alkaline phosphatase activity in the pellet is retained at the origin (fig. $1 \mathrm{~F}$ ). Pellet extracts with butanol at $\mathrm{pH} 5.0$, run under same condi-
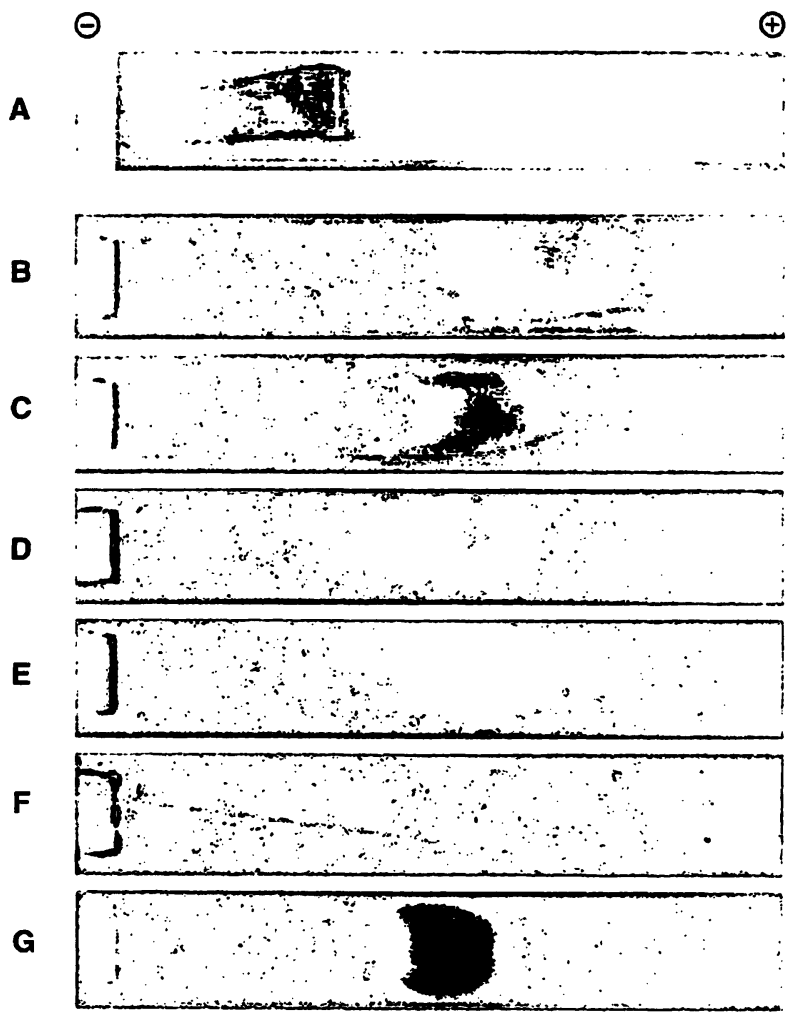

Fig. 1 Alkaline phosphatase electrophoretic patterns in polyacrylamide gels.

A - Suspension of amniotic fluid $100000 \mathrm{~g}$ pellet treated with Triton X-100.

B - Butanolic extract at pH 5 from suspension of amniotic fluid $100000 \mathrm{~g}$ pellet.

$\mathrm{C}-$ Butanolic extract at $\mathrm{pH} 5$ from suspension of amniotic fluid $100000 \mathrm{~g}$ pellet treated with neuraminidase.

D - Butanolic extract at pH 5 from meconium treated with neuraminidase.

E - Butanolic extract at pH 5 from meconium.

$\mathrm{F}$ - Suspension of $100000 \mathrm{~g}$ pellet from amniotic fluid without Triton $X-100$.

$\mathrm{G}$ - Butanolic extract at pH 5 from adult intestinal tissue. 
tions, showed a region of staining with a mobility about twice as fast as that of the original preparation treated with Triton X-100 (fig. 1B). When the pellet butanolic extract was previously incubated with neuroaminidase $0.2 \mathrm{kU} / \mathrm{l}$ at $37^{\circ} \mathrm{C}$ for $2 \mathrm{~h}$ the mobility of the band was slightly reduced (fig. 1C). Alkaline phosphatase extracted from meconium by butanol at $\mathrm{pH} 5.0$ treated and non-treated with neuraminidase presented the same velocity of migration as the band observed in the pellet preparations processed under the same conditions (fig. $1 \mathrm{D}$ and $1 \mathrm{E}$ ). The enzyme extracted from adult intestinal mucosa gave a band with the same mobility as those in the amniotic fluid pellet and meconium after incubation with neuraminidase (fig. 1G). Electrophoretic studies of the amniotic fluid $100000 \mathrm{~g}$ supernatant concentrated 20 times by ultrafiltration and incubated with neuraminidase to stress differences in mobility between the fetal intestinal alkaline phosphatase and the other isozymes present in amniotic fluid (placental and liver-bone-kidi ney alkaline phosphatase) revealed that no fetal intestinal alkaline phosphatase was present in the supernatant. Absolutely no activity could be detected in the region corresponding to fetal intestinal alkaline phosphatase (results not shown).

Assays of inhibition of the enzyme present in the pellet showed a behaviour similar to that of fetal (and adult) intestinal isozyme. In the presence of $2.5 \mathrm{mmol} / \mathrm{l} L$-phenylalanine, the enzyme showed a $60 \%$ inhibition; that extracted from meconium $65 \%$ and that from adult intestine $62 \%$. With $10 \mathrm{mmol} / \mathrm{l} L$-homoarginine, inhibition was $25 \%$ for the enzyme in the pellet, $20 \%$ for that from meconium and $21 \%$ for that in adult intestinal mucosa. Inhibition of the alkaline phosphatase contained in the supernatant after centrifugation at $100000 \mathrm{~g}$ was $52 \%$ with $L$-phenylalanine and $48 \%$ with $L$-homoarginine. Reported values of inhibition of the placental isozyme are $70 \%$ with $2.6 \mathrm{mmol} / 1 \mathrm{~L}$-phenylalanine and $9 \%$ with $10 \mathrm{mmol} / 1 \mathrm{~L}$-homoarginine and for liver-bone-kidneyisozyme, $9.5 \%$ and $80 \%$ for $L$-phenylalanine and $L$-homoarginine respectively (15).

\section{Determination of alkaline phosphatase isozyme activity in amniotic fluid}

The total alkaline phosphatase activity in amniotic fluid free of cells and debris (supernatant after $10000 \mathrm{~g}$ centrifugation) gave a mean value of 25.0 (s.d. 6.6) $\mathrm{U} / \mathrm{l}$ in 30 samples. This value corresponds to $100 \%$ activity. Since practically all the fetal intestinal alkaline phosphatase is separated in the $100000 \mathrm{~g}$ pellet, the alkaline phosphatase activity of the supernatant after $100000 \mathrm{~g}$ centrifugation subtracted from total activity gives the amount of intestinal alkaline phosphatase. The mean value for this fraction was 20.3 (s.d. 6.6) U/l, which corresponds to $81 \%$ of the total activity. It is known that the placental isozyme is more stable to heat than the other isozymes (16). Activity in the supernatant after heating at $56^{\circ} \mathrm{C}$ for 90 min corresponds only to the placental alkaline phosphatase because the other isozymes are inactivated by such treatment. Its mean value was 1.85 (s.d. 1.35 ) $\mathrm{U} / \mathrm{l}$ or $7.5 \%$ of the total. Liver-bone-kidney alkaline phosphatase activity is the difference between enzymic activity in supernatant minus remaining activity after heating (placental isozyme). Thus, the difference of alkaline phosphatase in the supernatant and placental isozyme corresponds to the liver-bone-kidney isozyme. The average value was 2.9 (s. d. 1.7) $\mathrm{U} / \mathrm{l}$ or $12 \%$ of the total.

\section{Discussion}

The method presented allows determination of the three isozymes of alkaline phosphatase (fetal intestinal, placental and liver-bone-kidney) present in amniotic fluid. The proportion of each of the molecular forms obtained with this technique in amniotic fluid during the second trimester of pregnancy is similar to that found by other authors using immunochemical methods or combined inhibitors $(9,10)$.

The fetal intestinal alkaline phosphatase is the most abundant isozyme in amniotic fluid from the 15th to the 20th week of gestation. This form is associated with the microvilli which are continuously being sloughed and incorporated into the meconium and finally suspended in the amniotic fluid. This isozyme in the amniotic fluid is bound to membranous structures forming an aggregate or complex with a molecular mass greater than one million (14). As demonstrated by our results, this complex can be precipitated by centrifugation at $100000 \mathrm{~g}$ for 90 min. Previously, we had communicated the separation of high $M_{\mathrm{r}}$ (biliary alkaline phosphatase), another membrane-associated alkaline phosphatase from serum of cholestatic patients, using a similar procedure (17).

The fraction obtained in the $100000 \mathrm{~g}$ pellet of amniotic fluid showed the electrophoretic characteristics and inhibition by $L$-phenylalanine and $L$-homoarginine typical of fetal intestinal alkaline phosphatase. Absolutely no fetal intestinal alkaline phosphatase activity could be detected in the supernatant of $100000 \mathrm{~g}$. Conversely, only the fetal intestinal isozyme was found in the pellet, which did not show contamination with other isozymes.

Although the advances of molecular biology offer techniques with a high degree of accuracy, alkaline phosphatase determination in amniotic fluid is still a convenient method for most clinical laboratories. 
The procedure presented here further simplifies the technique, since it does not require the use of control isozymes, monoclonal antibodies or use of combined inhibitors to determine the fetal intestinal alkaline phosphatase. Further investigation is required to assess the possible usefulness of this method for the prenatal diagnosis of cystic fibrosis.

\section{References}

1. Mullivor RA, Mennuti MT, Harris H. Origin of alkaline phosphatase in amniotic fluid. J Obstet Gynecol 1979; 135:77-81.

2. Muller F, Berg S, Frot JC, Bouer J, Bouer A. Prenatal diagnosis of cystic fibrosis I: prospective study of 51 pregnancy. Prenat Diagn 1985; 5:97-108.

3. Papp Z, Toth A, Szabo M, Teichmann F, Szeifert GT, Toth M, Totok O. Early prenatal diagnosis of cystic fibrosis by ultrasound. Clin Genet 1985; 28:356-8.

4. Gilbert F. Genetic diagnosis and population screening of cystic fibrosis. Nature $1985 ; 318: 382-4$.

5. Brock DJH. Amniotic fluid alkaline phosphatase isoenzymes in early prenatal diagnosis of cystic fibrosis. Lancet 1984; I: 102.

6. Tsui LC, Buchwald M, Barker D, Bramn JC, Knowlton R, Schumm JW, et al. Cystic fibrosis locus deffined by a genetically linked polymorphic DNA marker. Science 1985; 230:1054-7.

7. Wainwright BJ, Scambler PJ, Schmidtke J, Watson EA, Law $\mathrm{H}$, Farrall $\mathrm{M}$, et al. Localization of cystic fibrosis locus to human chromosome 7q22. Nature 1985; 318:384.

8. White $R$, Woodward $S$, Leppert $M$, O'Connell $P$, Hoff $M$, Herbst J, et al. A closely linked genetic marker for cystic fibrosis. Nature $1985 ; 318: 382-4$.

9. Mullivor RA, Hanning VL, Harris H. Quantitative analysis of alkaline phosphatase in serum and amniotic fluid: comparison of biochemical and immunologic assays. J Lab Clin Med 1985; 105:342-8.

10. Brock DJH, Barron L, Bedgoof D, van Heyningen V. Prenatal diagnosis of cystic fibrosis using a monoclonal antibody specific for intestinal alkaline phosphatase. Prenat Diagn 1984; $4: 421-6$

\section{Acknowledgements}

We thank Dr. Antonio Blanco for advice and critical revision of the manuscript. This work was partially supported by a grant from the Consejo de Investigaciones Científicas y Tecnológicas de la Provincia de Córdoba (CONICOR) and the Secretaria de Ciencia y Tecnología de la Universidad Nacional de Córdoba (SECyT).

11. Morton RK. The purification of alkaline phosphatase of animal tissues. Biochem J 1954; 57:595-603.

12. Walter K, Schutt Ch. Methods of enzymatic analysis, 2nd edn. Bergmeyer HU, editor. New York: Academic Press, 1974:856-60.

13. Ogita Z, Markert CL. A miniaturized system for electrophoresis on polyacrylamide gels. Anal Biochem 1979; 99:233-41.

14. Moss DW, Whitaker KB. The physical characteristics and enzymatic modifications of fetal intestinal alkaline phosphatase in amniotic fluid. Clin Biochem 1987; 20:9-12.

15. Vergner HA, Brisson Longarre A, Grozdea JG, Blum CJ, Kihn Y, Sevely J. Nuclear localization and characterization of alkaline phosphatase in neutrophils from normal controls and pregnant women. Ann J Hematol 1992; 39:249-56.

16. Vengerov $Y$, Gudima AV, Voronov AV, Votrin I. Immunochemical studies of human placental alkaline phosphatase in normal and neoplastic tissues. In: Weber G, editor. Advances in enzyme regulation, New York: Pergamon Press, 1988:345-54.

17. Moreno J, Vera MC, Yorio M. Methods for determining high$\mathrm{Mr}$ (biliary) alkaline phosphatase in plasma. Clin Chem 1992; 36:319-20.

Dr. José Moreno Barral

Cátedra de Química Biológica

Facultad de Ciencias Médicas

Universidad Nacional de Córdoba

Casilla de Correo 35 , Suc. 16

5016 Córdoba

Argentina 